\title{
On the Relationship Between Information Management and Digitalization
}

\author{
René Riedl • Alexander Benlian · Thomas Hess • \\ Dirk Stelzer $\cdot$ Hermann Sikora
}

Published online: 27 October 2017

(C) Springer Fachmedien Wiesbaden GmbH 2017

\section{Outline of this Discussion Paper and Conceptual Foundations}

Digitalization is the process of introducing digital technologies, which essentially deal with changes caused by information technologies (Hess 2013). Currently, digital transformation is taking place in business and society at a stunning pace. This discussion paper is based on a panel at the 13th International Conference on Wirtschaftsinformatik. It seeks to shed light on the relationship between information management and digitalization. This relationship is important because it can be argued that digitalization mainly deals with concepts, tasks, and methods that are already covered by established information management frameworks. However, it can also be maintained that digitalization addresses new phenomena, a fact that, along with other arguments (e.g., attraction of attention to increase funding opportunities), should lead to the

Prof. Dr. R. Riedl ( $₫)$

University of Applied Sciences Upper Austria, Wehrgrabengasse

1-3, 4400 Steyr, Austria

e-mail: Rene.Riedl@fh-steyr.at

Prof. Dr. R. Riedl

University of Linz, Altenberger Strasse 69, 4040 Linz, Austria

Prof. Dr. A. Benlian

TU Darmstadt, Darmstadt, Germany

Prof. Dr. T. Hess

University of Munich (LMU), Munich, Germany

Prof. Dr. D. Stelzer

TU Ilmenau, Ilmenau, Germany

Hon.-Prof. Dr. H. Sikora

Raiffeisen Software, 4020 Linz, Austria establishment of a separate research field and a main teaching area in tertiary education. The present paper, which complements existing discussion papers on digitalization (e.g., Legner et al. 2017), discusses the relationship between information management and digitalization, and it is hoped that this discussion will instigate further discourse, both in academia and practice.

\subsection{Information Management and Digitalization}

According to Krcmar (2015, p. 1), information management (IM) is a critical part of an organization's management function and has the task of ensuring the best possible use of information for the organization's goals. Heinrich et al. (2014, p. 4) indicate that IM is an established research and teaching field in Business and Information Systems Engineering (Wirtschaftsinformatik, hereafter BISE), which has been developing since the 1980s and whose results have led to a remarkable output in academic literature (ranging from journal and conference publications to seminal textbooks). There is agreement in the scientific community that IM deals with the management of data, information, systems, technology, processes, and organizational strategy (Heinrich et al. 2014; Krcmar 2015; Mithas et al. 2011).

This relatively broad view of IM, encompassing all corporate levels from strategic to operational, contrasts with the concept of IT management, which predominantly concerns the management of software applications and the underlying technological infrastructure. Thus, while IM is a management concept that, by definition, deals with topics that range from strategic to operational (e.g., strategic topic: the contribution of the IT function to competitive advantage, operational topic: IT service level monitoring), IT management mainly deals with operational topics (Heinrich et al. 2014; Krcmar 2015). 
So far, conceptual distinctions between IM, IT management, and other related areas (e.g., information systems management) have not played a significant role in BISE. However, due to the increasing importance of digitalization in business and society, the following question has become critical: What is the relationship between IM and digitalization?

Discussing this question is of high relevance because a 2017 guideline for BISE in tertiary institutions ("Rahmenempfehlung für die Ausbildung in Wirtschaftsinformatik an Hochschulen") defines twelve main areas of education ("Hauptausbildungsbereiche"), two of which are "information management" and "digital transformation" (for details, see Jung and Lehrer 2017). While IM has already been a major area of education in prior versions of the recommendation, digital transformation was added in the 2017 version. Importantly, the working group behind the recommendation (BISE professors and practitioners) highlight that IM has an interrelationship with other topics, in particular with digital transformation. In view of this interrelationship, it is useful to continue the discussion initiated by the working group, aiming at a consensual understanding of the relationship between IM and digitalization.

Another reason why the present paper contributes to the academic literature is related to the empirical finding that BISE, if compared to international Information Systems (IS) research, is subject to a greater risk of placing too much emphasis on fads (Steininger et al. 2009). One may argue that, unlike many other past IS topics, digitalization will most likely not be a fad. However, because it is not possible to know whether digitalization (as a term or concept) will stay important in the future, it cannot be ruled out that digitalization will become another fad. For example, as described in Steininger et al. (2009, pp. 416-417), it turned out that e-commerce was a fad, despite its enormous relevance in the late 1990s. It follows that it is possible that a look back at 2017 in 5 or 10 years will reveal that digitalization was just another fad. However, it is also possible that the current emergence of digitalization marks the beginning of the most important thematic development in the entire history of BISE and IS.

\subsection{Relationship Between IM and Digitalization: Three Major Scenarios}

Several views and corresponding options exist regarding how BISE can deal with the new emerging area of digitalization in the light of its relationship with the established area of IM. Three major scenarios are described in the following.

First, the emerging subject area, digitalization, is subsumed under the established area, IM, provided that the existing IM frameworks permit an integration of the content. Hence, digitalization is a subcategory of IM in this scenario. This would imply that phenomena of digitalization become integrated into existing IM task taxonomies. Heinzl and Uhrig (2016, original in German) state that "tasks of strategic information management can be cited, which have the potential to absorb phenomena of digitalization" (p. 37), and they indicate situation analysis, goal planning, strategy development, and action planning as example tasks.

Second, the phenomena in the emerging subject area, digitalization, significantly differ from the phenomena in the established area, IM. It follows that while in scenario 1 I assume that digitalization phenomena can be subsumed under IM, scenario 2 assumes a significant phenomenological difference. Of course, such a significant difference in content does not mean that the two areas, IM and digitalization, are completely disjoint sets (such an assumption of completely disjoint sets is possible in theory, but not in practice). Rather, I argue that the intersection is not too large (e.g., $<50 \%$ ). A significant difference in content between IM and digitalization should result in the establishment of a new research and teaching field. Whether digitalization phenomena differ significantly from IM phenomena will be discussed in this paper, and this discourse should be continued in future papers.

Third, concepts such as "digitalization", "digital value creation", "digital transformation", "digital disruption", or "digital business strategy" comprise tasks and methods which are already included in existing IM frameworks (Heinrich et al. 2014; Krcmar 2015). In particular, strategic objectives and tasks (e.g., Bharadwaj et al. 2013; Matt et al. 2015; Walchshofer and Riedl 2017) are subsumed under the prefix "digital", some of which have long been included in IM frameworks. As an example, the strategic impact of information resources on corporate strategies and business success is well documented in IM textbooks (e.g., Heinrich et al. 2014; Krcmar 2015) and related publications (e.g., Applegate et al. 2007). Thus, if strategic IM tasks (e.g., situation analysis, goal planning, strategy development, or technology management), along with corresponding methods [see, e.g., the methods described in Heinrich et al. (2014) and Krcmar (2015)], are established as major components in the upcoming area of digitalization, IM might lose its strategic dimension, thus being reduced to an operational domain with little strategic relevance.

Figure 1 conceptually summarizes three major scenarios for the relationship between information management (IM) and digitalization (D). In scenario A, D is shown as a subset of IM. In scenario B, IM and D are largely independent areas with different underlying phenomena (yet, both areas may share a subset of common topics). In 


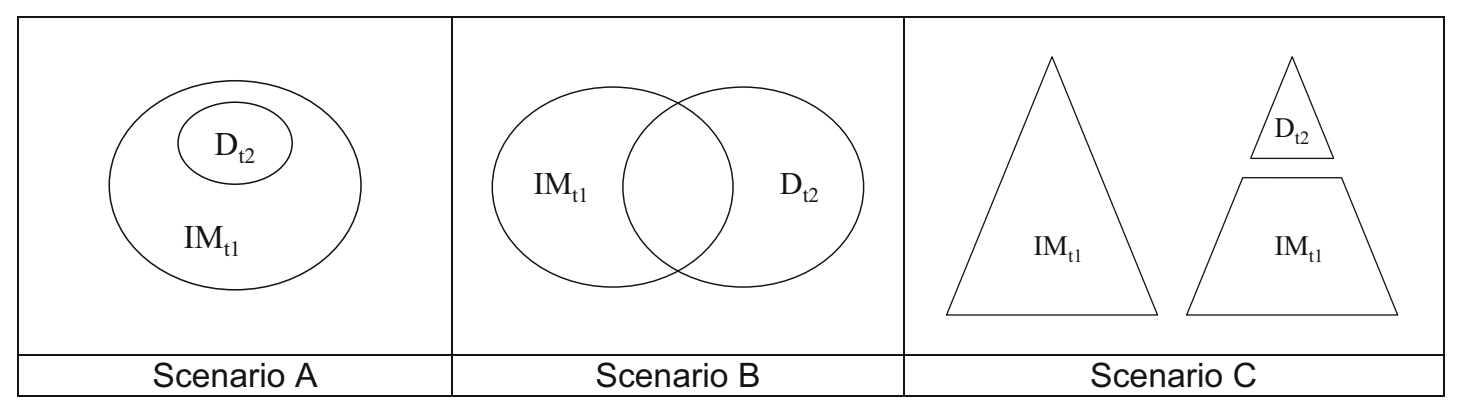

Fig. 1 Three major scenarios on the relationship between information management (IM) and digitalization (D). $t_{1}$ and $t_{2}$ indicate that IM existed before D

scenario $\mathrm{C}$, I illustrate that many digitalization phenomena deal with topics related to strategic IM [note that the pyramid conceptually illustrates an organization, the top of which signifies the strategic level and the bottom the operational level, after Heinrich et al. (2014)].

\subsection{Contributions}

In the first two following contributions, Alexander Benlian and Thomas Hess argue that digitalization and digital transformation should be defined as an independent research and teaching field. It follows that their opinion strongly corresponds to scenario $\mathrm{B}$ and scenario $\mathrm{C}$ in Fig. 1, respectively. In the subsequent contribution, Dirk Stelzer advances a different view, namely one that significantly corresponds to scenario A in Fig. 1. Finally, Hermann Sikora, CEO of a large Austrian software firm, complements the preceding academic perspectives with a practitioner's view.

Prof. Dr. René Riedl, University of Applied Sciences Upper Austria and University of Linz

\section{Digital Transformation (DT) as a Unique Research Field}

I assume the position that DT should be established as a unique research field in BISE, in which DT and IM share some common ground but also examine distinct phenomena (cf. Fig. 1, scenario B). Two main lines of argument that are based on substantive and strategic reasons support this position.

On the one hand, DT covers units and levels of analysis that partially differ or go beyond those typically examined in IM research. DT research typically places strong emphasis on the customer interface and on how information and communication technologies (ICTs) affect business concepts such as processes, services, and products. DT even goes so far as to look at how information is embedded in products and services (i.e., "productization of data") and thus how information can be a core feature of digital products or innovative business models (Hess et al. 2016), an aspect which has often been neglected in previous IM research. In addition, DT research often assumes a broader and more far-reaching perspective when it comes to tracing the transformative implications of ICTs across various domains. For example, DT research examines how the boundaries between work and life domains become increasingly blurred due to the pervasiveness of ICT and digital workplaces, which is clearly outside the confines of IM research. Moreover, how do digital platforms transform entire industries? Investigating how IT startups (e.g., fintechs, insurtechs) endanger incumbents in various industries (e.g., banking, logistics, media) and disrupt long-held market rules via the enabling capacity of ICTs and digital platforms is a core research area of DT, but not of IM.

On the other hand, separating DT from IM research and establishing it as a unique teaching area in academic education is also desirable from a pragmatic and strategic point of view. It not only increases the odds to acquire research funding and become the (natural) owner of digitalization topics in university curricula for BISE scholars. It is also a unique opportunity for IT leaders in companies (e.g., CIOs or head of IT department) to extend their area of responsibility into more strategic domains. I will briefly elaborate on these three aspects below.

First, digitalization in general and DT in particular are fundamental and long-lasting research topics that have been incorporated into the agendas of many funding organizations worldwide today (e.g., BMBF, NSF). These organizations acknowledge the enduring relevance of digitalization for firms, societies, and economies. Given these developments, establishing DT as a distinct research field would help BISE scholars target such research programs more forcefully (e.g., by clearly framing research projects around digitalization and DT) and send an important signal to rival disciplines (e.g., computer science, mechanical engineering) vying for the same funding sources. Ultimately, it would be desirable to establish BISE at the 
forefront of public awareness and discourse when it comes to discussing DT and its implications.

Second, BISE scholars are the natural owners of DT courses in university curricula given their interdisciplinary expertise and knowledge about IT artifacts and their technical, business and social implications. Several other disciplines at universities (such as marketing or mechanical engineering), however, have started to "occupy" the digitalization turf by offering their own courses on DT. This is often to the detriment of BISE which has so far not clearly communicated to students and university leadership that it provides the essential ingredients to teach this topic on a large scale. Of course, digitalization has many facets and should be examined from different and interdisciplinary angles in research and education. When other disciplines, however, start claiming digitalization and DT topics exclusively for themselves, the BISE discipline has to send a clear signal that DT is at the core of its teaching areas in academic education.

Finally, extending CIOs' area of responsibility to digitalization and DT topics promises that IT leaders in organizations have more strategic conversations with the CEO and stronger business impact in the future (Benlian and Haffke 2016). All too often, the CIO is perceived as someone who operates in a service delivery capacity or in a support function rather than in a strategic advisory role. Strategic topics around innovative digital business models and the implications of disruptive digital technologies for firm strategy (e.g., Blockchain, Big Data, or Cloud Computing) are covered by other executives (e.g., COOs or CMOs) more often than not, while CIOs are relegated to the sidelines and have to content themselves with managing the IT function. The advent of strategic topics that are increasingly driven by digitalization, however, offers IT executives the opportunity to increase in importance and status within companies, provided that they actively claim a large share of the digitalization turf and fully embrace all opportunities and risks of this "status upgrade" (Haffke et al. 2017).

In summary, all scientific disciplines have to evolve over time to make scientific progress and build cumulative knowledge. Regularly adapting research topics and teaching areas in substantial ways is one important measure to move a discipline forward. In contrast, pigeonholing powerful new phenomena into old categories bears the risk that these old categories become bloated and shapeless, and that scientific progress eventually stalls. There is a lot to gain from DT - understood and positioned as a separate area with novel and unique perspectives - because it entails manifold opportunities to advance our field in research, teaching and practice.

Prof. Dr. Alexander Benlian, TU Darmstadt

\section{Management of the Digital Transformation as a Stand-Alone Topic in Information Systems Research}

\subsection{Two Levels of Digital Transformation}

Digital transformation represents a challenge for companies on two levels. On the first level, companies are seeking digital-driven business innovations, such as a new form of customer interaction based on online channels and improved customer relationship management systems. Other companies are thinking about new ways of generating revenue, for example in the form of so-called freemium revenue models. All these challenges deal with concrete changes in processes, products, and business models.

On a second level, companies are also confronted with the challenge of steering the process of digital transformation, referring to the identification, realization and implementation of new processes, products and business models. This includes, for example, the advantages and disadvantages of the establishment of a Chief Digital Officer or the process definition for the formulation of a digital transformation strategy. In the context of this article, the second level (the management of the digital transformation process) is the main focus.

\subsection{The Task-Related Perspective}

For the management of digital transformation it is an obvious approach to rely on the established concepts of information management. For this purpose, first the concept of information management in the form of Krcmar (2015) is considered in more detail. Krcmar (2015, p. 107) distinguishes the management of the information economy, the management of the information systems, and the management of the information and communication technology as so-called management tasks of information management. The management of the information economy is about the optimal provision of information in the company, also taking new technical solutions into account. Central tasks are the collection of information requirements as well as the structuring and networking of the information sources. The management of the information systems deals with individual application systems as well as the application system landscape. Important tasks are the sourcing of the applications (make-or-buy), the coordination of the system landscape and the operations of the software systems. The management of information and communication technology takes care of the infrastructure required for these applications. Specific tasks are the assessment of available technical developments, the 
integration of new solutions as well as the assurance and long-term planning of a reliable infrastructure.

The management of information systems and the management of information and communication technology play only a marginal role in the context of digital transformation. The situation is different with the first subject area, the management of the information economy. This topic is the central theme in the context of the management of digital transformation. However, this subject area is now addressed entirely differently in the context of digital transformation than in the context of the management of the information economy. As part of the management of the information economy, from a functional view access to the data and their processing always takes place in a more abstract form (see, e.g., Heinzl and Uhrig 2016). In addition, this is always at the core of the preparatory work for the development of an application system. Within the management of the digital transformation, in contrast, the digital-driven business innovation (for instance a new product or a new process) is the core. I therefore advocate the scenario $\mathrm{C}$ (cf. Fig. 1) as described above - and as it already has been implemented, for example, in the latest edition of the introductory book by Mertens et al. (2017).

\subsection{The Actor-Oriented Perspective}

An analysis based on data and its processing requires specific know-how in data and function modeling. This know-how is necessary for the development of new business concepts, but is by no means sufficient. Depending on the specific subject matter, concrete knowledge about markets and customer behavior, the preferences of employees or, for example, specific challenges in human resources management or accounting are sufficient.

The question remains whether the management of the information systems, the management of the information and communication technology, and the included management of the digital transformation should be brought together in an overarching concept. If one considers the tasks behind these three thematic fields, such an integration would not be appropriate. The first two topics are about information that is processed in applications or exchanged via infrastructures. In the third topic area, however, the (IT-based) business solution is at the center, meaning that the objects of the analysis differ. From the perspective of the actors, I therefore advocate scenario $\mathrm{C}$ (cf. Fig. 1).

Prof. Dr. Thomas Hess, University of Munich (LMU)

\section{Digitalization: Fad? Main Area of Education?}

In this section, I will discuss whether digitalization is a fad and whether it should be included as a main area of education in recommendations for university curricula.

\subsection{Is Digitalization a Fad?}

I define a fad as a form of collective behavior which enthusiastically focuses on a particular concept or label for a finite period of time. That does not necessarily mean that the topic underlying the fad was irrelevant before the fad started. Neither does it mean that the topic will be irrelevant after the fad has come to an end. However, the topic receives excessive attention from practitioners, scholars, politicians, and in the public perception, although the significance of the underlying topic has not changed fundamentally. When the fad comes to an end, the hype is over although the underlying topic may still be highly relevant.

A popular example for describing fads in IT is Gartner's Hype Cycle which structures technology-driven fads into phases, namely, technology trigger, peak of inflated expectations, trough of disillusionment, slope of enlightenment, and plateau of productivity (Linden and Fenn 2003).

A survey of the literature reveals that scholars discussing digitalization and related concepts (e.g., digital transformation, digital strategies) essentially consider five topics: digitalization of business activities, digitalization of products and services, digital business models, digital business and IT strategies, and change and transformation processes relating to digitalization (Berman and Bell 2011; Bharadwaj et al. 2013; Hess 2013; Mithas et al. 2013; Matt et al. 2015).

I postulate that most of these topics have always been dealt with by IM. I will discuss this in the following paragraphs.

Automation of business activities, tasks, functions, and processes is usually supported by digital technologies and has always been a key issue in BISE (Davenport and Short 1990; Hammer and Champy 1993). Digitalization of products and services also has a long tradition in BISE, at least since the rise of the World Wide Web (Shaprio and Varian 1999). Automotive IT and healthcare IT are current examples of this topic area. Redesign and innovation of business models due to novel opportunities and risks relating to digitalization have also been discussed by scholars at least for the last 20 years (Timmers 1998). Changes and transformations of governance, management, strategy, and structure of organizations triggered by IT innovations are subjects of strategic IM, strategic 
alignment, or business-IT-alignment, respectively (Henderson and Venkatraman 1993).

The adoption of IT innovations by organizations has required change management support at all times. Consequently, design and support of transformation processes, usually labeled change management, is a well-known topic area in IM. A few examples should serve to illustrate this: individual data-processing supported by personal computers, office-software packages, and local area networks in companies that had previously used mainframes or midrange-computers; the adoption of standard software packages, e.g., ERP systems, in corporations that used customized individual software before, or business process management initiatives striving for process efficiency supported by information technology. Consequently, scholars have been exploring transformation processes related to digitalization for more than 50 years (e.g., Mann and Williams 1960).

I conclude that digitalization is not a new topic for BISE or IM. The current emphasis on digitalization rather indicates that it is a fad. Over the last 50 years, scholars and practitioners have used various labels for the phenomenon of increasing digitalization, e.g., automation, computer aided or software supported xyz. However, the underlying concept has always been the same. I dare to maintain that the current fad called digitalization does not seem to add significant news to IM.

\subsection{Should Digitalization Become a Main Area of Education?}

As already mentioned before, "information management" and "digital transformation" have both been included as main areas of education ("Hauptausbildungsbereiche") in the 2017 guidelines for higher education in BISE (Jung and Lehrer 2017). There is some controversy as to whether this was a wise decision or not.

How did our colleagues handle fads in previous versions of the recommendations for higher education in BISE? One of the most prominent fads at the end of the 1980s and the beginning of the 1990s was artificial intelligence and expert systems, respectively (Mertens 1995). This topic was not included as a main area of education in the 1992 version of the recommendations (GI and WKWI 1992). Ten years later, at the turn of the millennium, the most dominant fad was electronic commerce/electronic business (Steininger et al. 2009). This topic was included as a main area of education in the 2003 version of the recommendations (GI and WKWI 2003). Only 4 years later, in the 2007 version of the recommendations (GI and WKWI 2007), the topic electronic commerce/electronic business was deleted as a main area of education.
From the development of the recommendations over the last 25 years, I conclude that including fads, e.g., artificial intelligence/expert systems or electronic commerce/business, or currently digitalization, is an option, however, it is not mandatory. Digitalization could have also been mentioned as an element of "information management".

An analysis of the two areas "information management" and "digital transformation" in the 2017 version of the recommendations reveals that there are several cross-references between the two areas. This shows that the authors of the recommendations have perceived numerous overlaps of the two areas. I conclude that including digitalization/ digital transformation as an element of "information management" would have been a permissible option.

\subsection{Summary}

I do not claim that digitalization is unimportant. Quite the contrary: digitalization is a key topic of BISE and of IM. It always has been and most probably will always be a central theme of our research and teaching discipline. However, the current "hype" surrounding digitalization seems to me as if biologists had suddenly discovered life as a key topic of teaching and research, or sociologists human behavior, or physicians health, etc. Neither am I suggesting that IM has explored digitalization with appropriate depth and breadth yet. I am, however, convinced that this venerable research and teaching tradition is able to take up the challenge and to make helpful contributions to the exploration and design of digital transformation.

Prof. Dr. Dirk Stelzer, TU Ilmenau

\section{Information Management and Digital Transformation: A Practitioner's Perspective}

The history of Information Technology (IT) from the viewpoint of practical application shows several (subsequent and thus overlapping) innovation processes, for example: computerization (1960s), data processing (1970s), personal computing (1980s), internet computing (1990s), and digitalization and digital transformation (2010).

These innovations were offered to the market by large international IT service providers, allowing the management of businesses and corporations to successfully incorporate IT and thus permitting the best possible support for business models and plans - IT as business enabler. This business-technical perspective from the 1960s marks the beginning of BISE (Heinrich 2012). 
The term 'digitalization' describes the process which leads society from the postindustrial information society into all aspects of the 'digital society' ('digitality') (Sikora et al. 2016). The carrier medium for this process is the internet, often perceived as a space and thus created as such. Digitalization will greatly challenge both social and economic powers. Therefore, it is logical that related transformation processes are of great interest to science in general and to information systems research in particular. During these transformation processes, which involve a wide range of social and economic entities, a new phenomenon will be reached: the development of (virtual) 'states' instead of just 'rooms' within (or based upon) the internet.

The term 'digital transformation' is used primarily to describe the transformation from partly digitized business and society models into fully digitized business and society models. As such, business models are completely based on 'digital levers' which are dependent on mechanisms unobtainable without the internet. The concept of 'digital transformation' therefore primarily deals with the managerial-technical viewpoint of business model transformation.

This process represents a major challenge for business management as all wide-reaching innovations or industrial revolutions do. Information Management must research this process to keep and not lose its key role as an applied business discipline. A main part of this research is the business management process of identification and use of 'digital levers' (transformation idea) to reach new digital business models (innovation). The practical relevance of business informatics however does not absolve information management from maintaining a consistent set of terms, definitions and concepts, independent of how radical and wide reaching actual IT developments might be. Contemplating the earlier introduced transformation processes in the history of IT, all have the following in common: their effective power in the operational reality depends upon the effectiveness of the given information management, since the focus of value creation is 'information'.

It is irrelevant which alternate term might be used for 'information management' and its tasks. It is also "irrelevant" how strong the awareness of the necessity of effective and efficient information management might be within corporations nowadays (sense of urgency). I perceive information management as an indispensable scientific discipline which is not yet sufficiently recognized as a core task in business management. Without effective information management, digitalization will not be able to create value, and therefore no long-term business survival. Within the digital economy, value creation is primarily based upon effective and efficient examination, interpretation, processing and forwarding of information - core tasks of information management. Digitalization is the "maximum accelerator" of the importance of information management.

Obviously, 'digital transformation' will not replace or supersede (the discipline of) information management. On the contrary, information management is the management discipline that makes the 'existence factor IT' manageable in the framework of people-task-technical-systems (Heinrich et al. 2011). On the other hand, it is clear and logical that the object of 'digital transformation' will find its way into the curricula of academic studies, e.g., of business informatics degree programs. Hereby, the clear positioning compared to information management is essential. To illustrate this, let me ask the following question: Does 'digital transformation' compare to information management as 'alphabetizing' does to education management? The term 'information management' and its concepts will be of relevance for a longer period than 'digitalization' and 'digital transformation'. From the viewpoint of practical application, too, it is essential to have and further develop a scientific discipline for information management, independent of novel transformation phenomena.

Therefore, I suggest that the relationship between information management and digital transformation within business informatics curricula should be shaped like scenario A or scenario B in Fig. 1. Scenario B emphasizes that within digital transformation there will be areas that might be outside of the information management concepts (as of today).

Also, I recognize arguments for scenario C in Fig. 1 in the sense that long ranging effects of digitalization will have an impact on all aspects of life. Thus, it is clear that the definition of information management will be put to the test according to breadth, depth, relevance, and practical suitability. This will allow for interesting up-to-date curricula. However, information management will not become obsolete or be replaced by 'digital transformation', because 'information' is timeless whereas 'transformations' are temporary, although recurring.

\section{Hon.-Prof. Dr. Hermann Sikora,} Raiffeisen Software

\section{References}

Applegate LM, Austin RD, McFarlan FW (2007) Corporate information strategy and management: text and cases, 7th edn. McGraw Hill, New York

Benlian A, Haffke I (2016) Does mutuality matter? Examining the bilateral nature and effects of CEO-CIO mutual understanding. J Strateg Inf Syst 25(2):104-126

Berman SJ, Bell R (2011) Digital transformation. Creating new business models where digital meets physical. IBM Global Business Services. Executive Report 
Bharadwaj A, El Sawy OA, Pavlou PA, Venkatraman N (2013) Digital business strategy: toward a next generation of insights. MIS Q 37(2):471-482

Davenport TH, Short JE (1990) The new industrial engineering: information technology and business process redesign. Sloan Manag Rev 4:11-27

Mann FC, Williams LK (1960) Observations on the dynamics of a change to electronic data-processing equipment. Adm Sci Q $5(2): 217-256$

GI and WKWI (1992) Gesellschaft für Informatik (GI) und Wissenschaftliche Kommission Wirtschaftsinformatik (WKWI): Rahmenempfehlung für Diplom-Studiengänge Wirtschaftsinformatik an Universitäten. Wirtschaftsinformatik 34(4):446447

GI and WKWI (2003) Gesellschaft für Informatik (GI) und Wissenschaftliche Kommission Wirtschaftsinformatik (WKWI): Rahmenempfehlung für die Universitätsausbildung in Wirtschaftsinformatik. Informatik-Spektrum 26(2):108-113

GI and WKWI (2007) Gesellschaft für Informatik (GI) und Wissenschaftliche Kommission Wirtschaftsinformatik (WKWI): Rahmenempfehlung für die Universitätsausbildung in Wirtschaftsinformatik. Informatik-Spektrum 30(5):362-372

Haffke I, Kalgovas B, Benlian A (2017) Options for transforming the IT function using bimodal IT. MIS Q Exec 16(2):101-120

Hammer M, Champy J (1993) Reengineering the corporation: a manifesto for business revolution. Harper Collins, New York

Heinrich L (2012) Geschichte der Wirtschaftsinformatik, 2nd edn. Springer Gabler, Wiesbaden

Heinrich LJ, Heinzl A, Riedl R (2011) Wirtschaftsinformatik Einführung und Grundlegung, 4th edn. Springer, Heidelberg

Heinrich LJ, Riedl R, Stelzer D (2014) Informationsmanagement: Grundlagen, Aufgaben, Methoden, 11th edn. De Gruyter Oldenbourg, Berlin

Heinzl A, Uhrig M (2016) Informationsmanagement im Zeitalter der Digitalisierung. Wirtschaftsinformatik und Management $8(2): 28-39$

Henderson J, Venkatraman N (1993) Strategic alignment: leveraging information technology for transforming organizations. IBM Syst J 32(1):472-484

Hess T (2013) Digitalisierung. Enzyklopädie der Wirtschaftsinformatik. http://www.enzyklopaedie-der-wirtschaftsinformatik.de/. Accessed 5 June 2016
Hess T, Matt C, Benlian A, Wiesböck F (2016) Options for formulating a digital transformation strategy. MIS Q Exec 15(2): $123-139$

Jung R, Lehrer C (2017) Guidelines for education in business and information systems engineering at tertiary institutions. Bus Inf Syst Eng 59(3):189-203

Krcmar H (2015) Informationsmanagement, 6th edn. Springer, Heidelberg

Legner C, Eymann T, Hess T, Matt C, Böhmann T, Drews P, Mädche A, Urbach N, Ahlemann F (2017) Digitalization: opportunity and challenge for the business and information systems engineering community. Bus Inf Syst Eng 59(4):301-308

Linden A, Fenn J (2003) Understanding Gartner's hype cycles. Strategic Analysis Report R-20-1971. Gartner

Matt C, Hess T, Benlian A (2015) Digital transformation strategies. Bus Inf Syst Eng 57(5):339-343

Mertens P (1995) Wirtschaftsinformatik - Von den Moden zum Trend. In: König W (ed) Wirtschaftsinformatik '95. Physica, Heidelberg, pp 25-64

Mertens P, Bodendorf F, Koenig W, Schumann M, Hess T, Buxmann P (2017) Grundzüge der Wirtschaftsinformatik, 12th edn. Springer, Heidelberg

Mithas S, Ramasubbu N, Sambamurthy V (2011) How information management capability influences firm performance. MIS Q 35(1):237-256

Mithas S, Tafti A, Mitchell W (2013) How a firm's competitive environment and digital strategic posture influence digital business strategy. MIS Q 37(2):511-536

Shaprio C, Varian HR (1999) Information rules: a strategic guide to the network economy. Harvard Business Review Press, Boston

Sikora H, Roithmayr F, Pomberger G (2016) Verändert das digitale Zeitalter die Anforderungen an die strategische Führungskompetenz? Wirtschaftsinformatik und Management 8(2):66-76

Steininger K, Riedl R, Roithmayr F, Mertens P (2009) Fads and trends in business and information systems engineering and information systems research: a comparative literature analysis. Bus Inf Syst Eng 1(6):411-428

Timmers P (1998) Business models for electronic commerce. Electron Mark 8(2):3-8

Walchshofer M, Riedl R (2017) Der Chief Digital Officer (CDO): Eine empirische Untersuchung. HMD - Praxis der Wirtschaftsinformatik 54(3):324-337 